\title{
ANAESTHETIC CONSIDERATIONS IN THE PROLONGED Q-T INTERVAL (LQTS): A CASE REPORT
}

\author{
Sidney Owitz, Vasilios Pratilas, Margaret G. Pratila and Ivan Dimich
}

IN 1957 Jervell and Lange-Neilson ${ }^{1}$ discussed the triad of prolonged Q-T interval, syncopal attacks due to ventricular fibrillation and congenital deafness. In the absence of congenital deafness. the otherwise identical condition is called the Romano-Ward syndrome. ${ }^{2,3}$ Both are transmitted as a hereditary trait. ${ }^{1}$ These conditions are seen in individuals with clinically normal hearts ${ }^{3}$ but the mortality rate is very high. Termination in sudden death is 73 per cent in those who are untreated. ${ }^{4}$

Patients with prolonged Q-T syndrome are at obvious risk of developing serious dysrhythmias during any period of stress or emotional disturbance, including surgery and anaesthesia. Induction of anaesthesia or the use of such agents as epinephrine may precipitate ventricular tachycardia or fibrillation.

One of the present forms of therapy of the long Q-T syndrome (LQTS) is stellate ganglion blockade,,$^{13}$ usually done prior to surgical ablation of the stellate ganglion. This block is usually done by an anaesthetist and it is for more than mere academic interest that the anaesthetist should understand this syndrome and be aware of its dangers.

\section{Case history}

The patient was a 33-year-old female admitted to the hospital because of spells of dizziness and palpitations. Ten years before admission she had been told that she had an irregular heart beat, but she was not treated and no further investigations were done. The patient never complained of chest pain, shortness of breath, or swollen ankles. There was no history of rheumatic fever, diphtheria, heart disease, a neurological condition or hypoglycaemia. She was not on medication and there were no known drug allergies. She

Sidney Owitz, M.D., Assistant Clinical Professor. Vasilios Pratilas, M.D.. Assistant Clinical Professor. Margaret G. Pratila, M.D., Assistant Clinical Professor, Department of Anesthesiology, Mount Sinai School of Medicine, C.U.N.Y., New York. N.Y., U.S.A.

Ivan Dimich, M.D., Associate Professor of Paediatrics, C.U.N.Y.. New York, N.Y., U.S.A. smoked one pack of cigarettes a week and did not take alcohol. There was no family history of heart disease, syncope or sudden death. The dizzy spells had occurred since childhood at intervals of approximately two months. They lasted from a few seconds to a few minutes, and only once did she faint. In the past three months these dizzy spells had become more frequent and occurred about twice each week.

On examination, her blood pressure was $110 / 70 \mathrm{~mm} \mathrm{Hg}(14.6 / 9.3 \mathrm{kPa})$ without orthostatic change. The pulse rate varied between 80 and 100 per minute with multiple irregularities. Her eyes, including the fundi, were normal. There was no thyroid enlargement. The lungs were clear. Clinically, there was no cardiac enlargement and the heart sounds were normal although the rhythm was irregular. The abdomen was soft and not tender, with no organ enlargement. Peripheral pulses were present and equal and there was no oedema of the extremities or phlebitis.

The electrocardiogram revealed multiple ventricular premature contractions with bouts of bigeminy and runs of ventricular tachycardia. The axis was normal and there were no ischaemic changes. The $\mathrm{Q}-\mathrm{T}$ interval was 0.48 seconds at a rate of 88 per minute. Chest X-ray showed some granulomatous changes in the left upper lobe. Serum electrolytes and enzyme studies were normal. Bundle of His studies confirmed a prolongation of the Q-T interval. An echocardiogram was normal.

Lidocaine $100 \mathrm{mg}$ was administered intravenously, but produced little change in the rate of ventricular premature contractions. Spells of dizziness continued despite a lidocaine infusion at the rate of $2 \mathrm{mg}$ per minute. Adequate digitalization with digoxin had no effect on the rhythm. Propranolol $10 \mathrm{mg}$ was given orally four times daily (q.i.d.) and was increased to $20 \mathrm{mg}$ q.i.d. and then to $40 \mathrm{mg}$. q.i.d. There was no improvement in her condition. A stress test was done at this time. No ischaemic changes were noted but the Q-T interval was increased.

A left stellate ganglion block was done using the anterior (paratracheal) approach with $15 \mathrm{ml}$ of lidocaine one per cent. Signs of Horner's syn- 


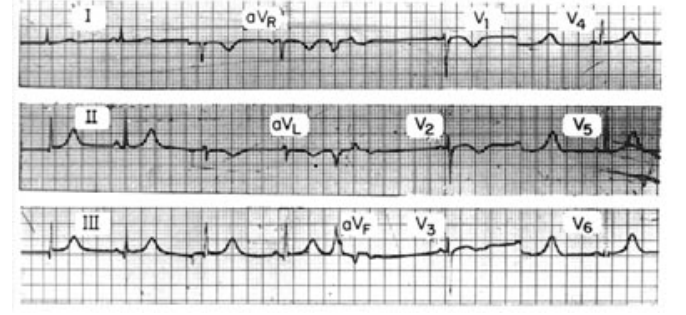

Electrocardiogram showing a prolonged Q-T interval of 0.48 second.

drome appeared and the Q-T interval decreased to 0.38 seconds. Normal sinus rhythm followed and lasted for 1.5 hours. The block was repeated on three occasions with the same result. A left sympathectomy was done, which produced a Horner's syndrome, but the dysrhythmia persisted. A second operation was done to divide the cardiac fibers which had been preserved at the first operation. The patient then reverted to normal sinus rhythm and this has been maintained. On each occasion premedication was morphine sulphate $20 \mathrm{mg}$ and scopolamine hydrobromide $0.4 \mathrm{mg}$ given intramuscularly one hour before operation. Anaesthesia was induced with thiopentone $250 \mathrm{mg}$ and succinyl dicholine $80 \mathrm{mg}$ intravenously. The trachea was intubated with an $8 \mathrm{~mm}$ tracheal tube and anaesthesia was maintained with nitrous oxide 3 litres and oxygen 3 litres per minute and enflurane 1.5 per cent.

\section{Discussion}

The onset of this syndrome usually accurs in infancy or early childhood. Symptoms, which may improve with age, include episodes of dizziness or syncope, loss of consciousness, and sudden death. Diagnosis is made on the history of syncopal attacks following emotional or physical stress associated with the electrocardiographic finding of a prolonged Q-T interval. ${ }^{4}$ Thirty per cent of all patients with the LQTS have associated deafness. The frequency of this syndrome in deaf-mute children is about 0.25 per cent. 5

The typical electrocardiographic finding is prolongation of the Q-T interval, which may be associated with abnormal or alternating $\mathrm{T}$ waves. ${ }^{4}$ The Q-T interval usually increases with exercise ${ }^{3-7}$ Exercise, stress or elevation in blood pressure (i.e. adrenergic stimulation) may precipitate ventricular bigemini or runs of multifocal ventricular premature beats. ${ }^{7}$ A prolonged $\mathrm{Q}-\mathrm{T}$ interval which is further prolonged by exercise is more vulnerable to the effect of epinephrine and ventricular fibrillation may be produced. ${ }^{8}$ The main factor in production of these dysrhythmias is the delay in ventricular repolarization. resulting in an increase in the vulnerable period for their development ( $R$ on $T$ ). ${ }^{9}$

The aetiology of these syndromes is still not certain. The most widely accepted explanation is an imbalance of adrenergic influences on the myocardium. A congenital decrease of activity in the right cardiac sympathetic nerves is usually found ${ }^{10}$ However, left sympathetic hyperactivity has also been demonstrated. The left stellate ganglion is responsible for inotropic effects and the right mainly for chronotropic effects. ${ }^{11}$

Since exercise and sympathetic discharge aggravates the condition, avoidance of strenuous activity and control of hypertension and tachycardia are advisable. Quinidine is contraindicated since it prolongs the Q-T interval. ${ }^{12}$ Diphenylhydantoin may shorten the Q-T interval and should therefore be beneficial in controlling the dysrhythmia. This, however, is not true clinically. Digitalis too has not been an effective treatment. The most effective drug therapy has been beta-adrenergic blocking agents, ${ }^{12}$ such as propranolol.

In those cases where medical treatment has been unsuccessful, a left stellate ganglion block should be done. It has been recommended that this should be done under general anaesthesia to reduce to a minimum the possibility of a sympathetic discharge and the onset of ventricular dysrhythmias. "This may be followed by surgical extirpation of the left stellate ganglion if the block has resulted in a shortening of the Q-T interval and a disappearance of the dysrhythmia. Most favorable long-term results are obtained by left stellate ganglionectomy. ${ }^{13}$ In those cases where block has suggested removal of the right stellate ganglion. Schwartz, et al ${ }^{4}$ have recommended bilateral ganglionectomy to avoid creating a dangerous imbalance with left prevalence. The aim of surgery is extirpation of the cardiac fibers or a preganglionic sympathectomy. Division of the fibers to the head alone is valueless. Horner's syndrome is insufficient evidence that cardiac fibers have been affected.

Garza $^{14}$ has stated the LQTS is less rare than it is unrecognized. Children do not generally have preoperative electrocardiograms, but those with a history of syncope, congenital deafness or a family history of sudden death should have a preliminary electrocardiogram to exclude LQTS. Garza's studies showed that ventricular dys- 
rhythmia was precipitated by three different mechanisms: (1) an increase in the systemic blood pressure (pressure induced extrasystoles); (2) sinus tachycardia, when the impulse reaches the ventricles which are still in a depolarized state; and (3) an extrasystole produced in the supernormal phase of repolarization ( $R$ on $T$ syndrome). Anaesthetic management of patients should avoid producing these conditions.

\section{Anaesthesia}

Patients with LQTS should be well sedated the night before operation and preoperatively to avoid sympathetic hyperactivity. The anaesthetic management of these patients must provide smooth induction and adequate depth of anaesthesia to avoid sympathetic stimulation.

Premedication with atropine is best avoided as it blocks the vagal inhibiting system of the heart, resulting in an unopposed acceleration from its sympathetic innervation. ${ }^{15}$ Barbiturates produce a negative chronotropic response. This is not blocked by atropine or propranolol but is partially antagonized by norepinephrine. ${ }^{16}$ Thiopentone would therefore appear to be a suitable agent for induction of anaesthesia in patients with LQTS. Ketamine has been shown to have a cardioaccelerating effect. ${ }^{17}$ This is believed to be due to central sympathetic stimulation ${ }^{18}$ and it should be avoided in patients with LQTS.

Although succinylcholine generally produces bradycardia due to vagal stimulation, Galindo and Davis ${ }^{19}$ have shown that it lowers the cardiac excitability threshold. This is explained on the basis of a sympathetic postganglionic stimulation combined with a direct myocardial effect. This could produce dysrhythmias. D-tubocurare has been shown to have antidysrhythmic effects. ${ }^{20}$ With d-tubocurare a slow pulse is often present, which is assumed to be due to increased vagal activity. ${ }^{21}$ Pancuronium produces a significant increase in heart rate which has been shown to be largely the result of vagolytic activity. ${ }^{22}$

Halothane has effects on phase 4 of the cardiac action potential which are more characteristic of an antidysrhythmic agent. It significantly reduces the cardiotoxicity of the digitalis compounds. ${ }^{23-24}$ Halothane-catecholamine dysrhythmias have been shown to be due to a reentry phenomenon. ${ }^{25,26} \mathrm{~A}$ critical level of blood pressure and atrial rate is necessary for induction of dysrhythmias. Methoxyflurane causes increases in heart rate mainly due to an increased rate of phase 4 depolarization. A combination of primary pacemaker depression and secondary pacemaker stimulation favors shift of pacemaker activity to the ventricular conducting system. ${ }^{27.28}$ The marked increase that methoxyflurane with epinephrine produces in phase 4 depolarization almost invariably results in dysrhythmias which originate in an ectopic pacemaker. Enflurane has a dose-dependent positive chronotropic effect of lesser magnitude than that produced by methoxyflurane and di-ethyl ether. ${ }^{29}$ It is known that enflurane causes alteration in the ionic movements of $\mathrm{Na}^{+} \mathrm{Ca}^{++}$and $\mathrm{K}^{+}$across the membrane during excitation-contraction coupling. ${ }^{30}$ Since Olley and Fowler ${ }^{12}$ have postulated that the final abnormality in LQTS is one of ionic movements across the cell membrane, enflurane may theoretically modify the incidence of dysrhythmias.

Cyclopropane enhances the slope of phase- 4 depolarization and potentiates that produced by epinephrine. It stimulates sympathetic activity. Dysrhythmias are common. ${ }^{32.33}$ Cyclopropane, is known to stimulate $\mathrm{Na}^{+}$transport across the membrane and produce hyperpolarization ${ }^{34}$ while halothane depresses $\mathrm{Na}^{+}$transport and causes depolarization. ${ }^{35}$ Di-ethyl ether has a direct positive chronotropic effect on atrial pacemakers $^{36}$ which is unimpaired by catecholamine depletion and is not due to direct beta-adrenergic receptor stimulation. This effect possibly explains the protective action of ether against cyclopropane-induced ventricular dysrhythmias, that is, an action similar to atrial pacing. ${ }^{37}$

Hauswirth ${ }^{38}$ has shown that droperidol produces an increase in the effective refractory period and, like other antidysrhythmic agents, decreases the speed of phase-O depolarization. Kern, et al..$^{39}$ reported that droperidol prolongs the functional refractory period by inhibiting the sodium carrying system. Grundy and Trittart ${ }^{40}$ have shown that low doses of meperidine cause a dose-dependent diminution of upstroke velocity in phase $\mathrm{O}$ of the cardiac action potential, associated with impairment of rate of conduction and excitability, but without a significant decrease in the resting potential or the height of the action potential. With higher doses the predominent effects are decrease in resting potential and in the height of the action potential, with a marked fall in upstroke velocity. This is thought to be due to the depression of the myocardial ATP-ase. Bradycardia occurs commonly during fentanyl administration. As with other opium alkaloids it is probably due to a central stimulation of the vagal cardio-inhibitory center leading to an 
increased release of acetylcholine at cholinergic fiber endings in the heart. ${ }^{41.42}$

Neostigmine has been reported to cause dysrhythmias. This is explained as being due to the inhibition by neostigmine of nor-epinephrine reuptake with the resulting intensification of catecholamine action. ${ }^{43}$

\section{SUMMARY}

A case of prolonged Q-T interval syndrome (LQTS) with ventricular dysrhythmias is presented. The patient was unresponsive to medical treatment. Left stellate ganglion block, followed by surgical excision of the ganglion, resulted in reversion to normal sinus rhythm. The causes of LQTS, its treatment and the effects of anaesthetic agents are discussed.

\section{RÉSUMÉ}

Un malade chez lequel un intervalle $Q-T$ prolongé était responsable d'épisodes arythmiques ventriculaires a été traité chirurgicalement après échec du traitement médical. Une stellectomie gauche a ramené le malade en rythme sinusal. L'on avait au préalable fait une épreuve thérapeutique au moyen d'un bloc du ganglion. Le syndrome du Q-T prolongé (Q-T prolongé. surdité congénitale et épisodes de fibrillations ventriculaires en situations de stress), le traitement du syndrome ( $\beta$-bloquants, chirurgie), et les implications anesthésiques sont présentés et discutés.

\section{REFERENCES}

1. Jervell, A. \& Lange-Nielsen, F. Congenital deaf-mutism, functional heart disease with prolongation of the Q-T interval, and sudden death. Am. Heart J. 54 : 59 (1957).

2. Romano, C.. Gemme, G. \& Pongiglione, R. Aritmie cardiache rare dell' eta pediatrica. Clin. Pediatr. 45: 656 (1963).

3. WARD, O.C. New familial cardiac syndrome in children. J. Irish Med. Assoc. 54: 103 (1964).

4. Schwartz, P.J.. Periti, M. \& Malliani, A. The long Q-T syndrome. Am. Heart J. 89: 378 (1975).

5. Cascos, A.S.. Sanchez-Harguindey L. \& De RabaGo, P.. Cardio-auditory syndromes: cardiac and auditory study of 511 deaf-mute children. $\mathrm{Br}$. Heart J. 31: 26 (1969).

6. van Bruggen, H.W., Sebus, J. \& van Heyst, A.N.P. Convulsive syncope resulting from arrhythmia in a case of congenital deafness with electro-cardiographic abnormalities. Am. Heart J. $78: 81$ (1969).

7. Phillips, J. \& IChinose, H. Clinical and pathological studies in the hereditary syndrome of a long Q-T interval, syncopal spells and sudden death. Chest $58: 236(1970)$.

8. Fastier, F.N. \& Smirk, F.H. Some properties of amerin, with special reference to its use in conjunction with adrenaline for the production of idio-ventricular thythm. J. Physiol. 107:318(1948).

9. JAMES, T.N. Q-T prolongation and sudden death. Mod. Conc. Cardiovasc. Dis. 38: 35 (1969).

10. Yanowitz, F., Preston, J.B. \& Abildskov, J.A. Functional distribution of right and left stellate innervation of the ventricles: production of neurogenic-electrographic changes by unilateral alteration of sympathetic tone. Circ. Res. 18: 416 (1966).

11. Randall, W.C. \& Rohse, W.G. The augmentor action of sympathetic cardiac nerves. Circ. Res. 4 : $470(1956)$.

12. Olley, F.M. \& Fowler, R.S.. The surdocardiac syndrome and therapeutic observations. Br. Heart J. 32: 467 (1970).

13. Moss. A.J. \& McDonald, J. Unilateral cervicothoracic sympathetic ganglionectomy for the treatment of long Q-T interval syndrome. N. England J. of Med. 285: 903 (1971).

14. Garza, L.A., Vick, R.L., Nora, J. \& McNamARA, D.G. Haritable Q-T prolongation without deafness. Circulation 4l: 39-48(1970).

15. Aviado, D.M., Drantz, \& Carr. Pharmacologic principles of medical practice. Baltimore. The Williams and Wilkins Company. p. 360 (1972).

16. ChiBa, S. \& Nacajima, T. Effect of sodium pentobarbital on the S.A. nodal activity of the dog heart in vivo. Tohoku J. Exp. Med. 106(4): 381 (1972).

17. Traber, D.L., Wilson, R.D. \& Prino, L.L. Differentiation of the cardiovascular effects of CI-581. Anesth, and Analg. 47: 769-778 (1968).

18. Traber, D.L.. Wilson, R.D. \& Priano, L.L. The effects of beta-adrenergic blockade on the cardiopulmonary response to ketamine. Anesth. and Analg. 49: 604-613 (1970).

19. Galindo, A. \& Davis, T. Succinylcholine and cardiac excitability. Anesthesiology 23: 32-40 (1962).

20. Wong, K.D.. Wyte, S.R., Martin, W.E. et al, Antiarrhythmic effects of skeletal muscle relaxants. Anesthesiology, 34: 458-462 (1971).

21. Gologorsky, V.A. \& Umanov, J.M. The mechanism of succinylcholine effect on the heart rate and rhythm. Progress in Anesthesiology. Proceedings of the Fourth World Congress of Anesthesiology. Amsterdam Excerpta Foundation, pp. 1165-1167 (1970).

22. Miller, R.D., Eger, E.I. II, Stevens, W.C. et al. Pancuronium-induced tachycardia in relation to alveolar halothane, dose of pancuronium and prior to atropine. Anesthesiology 42: 352 (1975).

23. Morrow, D.H. \& Townley, N.T. Anesthesiology and digitalis toxicity: an experimental study. Anesth. and Analg. 43: 510-519(1964).

24. Reynolds, A.K. \& HoRne, M.L. Studies on the cardiotoxicity of ouabain. Canad. J. Physiol. Pharmacol. 47: 165-170 (1969).

25. Hasimoti, K., ENdoh, M., Kimura, T. et al. Effects of halothane on automaticity and contractile force of isolated blood-perfused canine ventricular tissue. Anesthesiology 42: 15-25 (1975). 
26. Zink, J., Sasyniuk, B.I. \& Dresel, P.E. Halothane-epinephrine-induced cardiac arrhythmias and the role of heart rate. Anesthesiology 43: 548-555 (1975).

27. Arens, J.F. Methoxyflurane and epinephrine administered simultaneously. Anesth. and Analg. 47: 391-394 (1968).

28. Hudon, F. Methoxyflurane. Can. Anaes. Soc. J. 8: 544-550 (1961).

29. Krishna, G. \& Paradise, R.R. Mechanisms of chronotropic effects of volatile inhalation anesthetics. Anesth. and Analg. 56: 173-181 (1977).

30. Imatsuki, N., Shimosato, S. \& Etsten, B.E. The effects of changes in time interval of stimulation of mechanisms of isolated heart muscle and its response to ethrane. Anesthesiology 32: 11-16 (1960).

31. Olley, F.M. \& Fowler, R.S. The surdocardiac syndrome and therapeutic observations. Brit. Heart J. 32: 467-471 (1970).

32. Davis, L.V., Temte, J.V., Helmer, P.R., et al. Effect of cyclopropane and hypoxia on transmembrane potentials of atrial, ventricular and Perkinje fibers. Circul. Res. 18: 692-704 (1966).

33. Davis, L.D.. Temte, J.V. \& MurPhy, Q.R. Epinephrine cyclopropane effects on Purkinje fibers. Anesthesiology 30:369-377 (1969).

34. ANDERSon, N.B. Effect of general anesthetics on sodium transport in the toad bladder. Anesthesiology 27: 304-310 (1966).

35. ANderson, N.B. \& Shim, C.Y. Sodium transport and anesthetic requirements in the toad. Anesthesiology $34: 338-343$ (1971).
36. Krishna, G., Trueblood, M.S. \& Paradise, R.R. The mechanism of the positive chronotropic action of diethyl ether on rat atria. Anesthesiology 42: 312-318 (1975).

37. Lester, S., Cohen, L.S., Hilder, F.J., et al. Electrical stimulation of the atria in patients with an intact atrio-ventricular conduction system. Ann. N.Y. Acad. Sci. 167: 785-806 (1969).

38. Hauswirth, O. Effects of droperidol on sheep Purkinje fibers. Nauyn Schmiedebergs Arch. Pharmakol. 26l: 133-142 (1968).

39. Kern, R., Einwachter, H.M., HaAs, H.G. et al. Cardiac membrane currents as affected by neuroleptic agent: droperidol. Pfuegers Arch. 325: 262-278 (1971).

40. Grundy, H.F. \& Tritthart, H. Effects of pethidine and nalorphine on the mechanical and electrical activities of mammalian isolated ventricular muscle. Br. J. Pharmac. 46: 13-22 (1971).

41. Fennessy, M.R.\& Rathray, J.F. Cardiovascular effects of intravenous morphine in the anesthetized rat. Europ. J. Pharmacol. 14: 1-8 (1971).

42. Graves, C.L.. Downs, N.H. \& Brown, A.B. Cardiovascular effects of minimal analgesic quantities of Innovar ${ }^{-1}$, fentanyl and droperidol in man. Anesth. and Analg. 54: 15-23 (1975).

43. IVankovich, A.D., Miletich, D.J., Asham, S.Z. et al. Effects of neostigmine on potassium flux and $\mathrm{C}^{14}$ norepinephrine metabolism in the isolated heart. Abstracts of Scientific Papers. 1975 ASA Annual Meeting, pp. 329-330. 